\title{
Positive effect of pedometer-based walking intervention on body image and physical activity enjoyment in adolescent girls
}

\author{
Adam Kantanista ${ }^{1}$, Michał Bronikowski ${ }^{1}$, Ida Laudańska-Krzemińska ${ }^{2}$, Magdalena Król-Zielińska ${ }^{1}$, \\ Wiesław Osiński²
}

${ }^{1}$ Department of Didactics of Physical Activity, Poznań University of Physical Education, Poznań, Poland; ${ }^{2}$ Department of Physical Activity Study and Health Promotion, Poznań University of Physical Education, Poznań, Poland

\section{Summary}

Study aim: To assess the effects of an eight-week pedometer-based walking intervention, using different strategies of goalsetting, on self-efficacy, physical activity enjoyment, and body image.

Material and methods: The study included data from 82 girls, aged 16 to 18 years. The participants took part in the intervention using goal setting with the do your best strategy (do your best group, $\mathrm{n}=26$ ) or specific step goals predetermined by the researcher (predetermined goals group, $\mathrm{n}=56$ ). The group of participants from the predetermined goals group was divided into a group of those achieving the goals $(\mathrm{n}=28)$ and a group where goals were not achieved $(\mathrm{n}=28)$. Self-efficacy, body image, and physical activity enjoyment were assessed before and after the intervention.

Results: The results of ANOVA with repeated measures between the measurement times and groups showed a significant effect of body image $\left(F=3.60, p=0.03, \eta^{2}=0.08\right)$ and physical activity enjoyment $\left(F=3.10, p=0.05, \eta^{2}=0.07\right)$. Participants who achieved goals in step counts predetermined by the researcher had a more positive body image and a higher level of physical activity enjoyment after the intervention.

Conclusion: An eight-week pedometer-based walking program implemented in a school setting may improve body image and physical activity enjoyment in adolescent girls only if the set goals (the number of steps) are specific and fully achieved by participants. Using pedometers in conjunction with a goal setting program seems to be an effective motivational way to improve physical activity in female students.

Key words: Pedometer - Girls - Goal-setting - Body image - Self-efficacy - Physical activity enjoyment

\section{Introduction}

Physical activity improves health and reduces the risk of a number of adverse health outcomes, including cardiovascular disease mortality [9]. Girls have been found to be less active than boys, and a high percentage of girls do not reach the recommended level of physical activity [5]. Thus girls require more attention from parents and professionals.

Insufficient levels of physical activity among young people necessitate implementation of interventions enhancing physical activity, as well as interventions changing the level of psychological determinants of physical activity [11]. In recent years, the school setting has received attention in the field of health promotion and health behavior [28]. Physical activity programs in the school setting showed positive effects on psychological variables, activity behavior, health, and fitness outcomes (e.g., BMI, cardiovascular fitness, motor performance, daily minutes of vigorous physical activity, attitudes about physical activity and health, self-esteem, enjoyment and motivation for physical activity) $[3,7]$. Moreover, a systematic review by Lubans, Morgan, and Tudor-Locke [19] reported that pedometer-based interventions in adolescents enhanced their physical activity. Schools are in an ideal position to improve adolescents' health through physical activity. Health has the central role in the physical education curriculum, and physical education teachers can implement during-, before-, and after-school physical activity interventions. A pedometer is a simple device that can be used not only to evaluate physical efforts but also to motivate people to undertake physical activity. 
Goal setting, which is one of the strategies used in changing physical activity behavior, may be implemented together with pedometers. Goal setting is known to be effective in adults [12], but the literature on goal setting as a strategy for physical activity change for adolescents is limited [35]. Different strategies can be implemented in goal setting: goals may be self-set by the participants, collaborative, or prescribed (designed and chosen by the practitioner without input from the participant) [18]. As the result of a meta-analysis, Kang et al. [12] found that in adults, the strategy of 10,000 steps per day as a goal brings better results compared to a goal based on a baseline value of steps. Young people should perform more than 10,000 steps per day (including in school and leisure-time activity), which indicates that we should be looking for a new approach in goal setting.

In the current study, three different correlates of physical activity were taken into consideration: selfefficacy, body image, and physical activity enjoyment. Self-efficacy is commonly defined as the belief in one's ability to achieve a goal or an outcome, and the theory of self-efficacy was developed within the framework of social cognitive theory [1]. Self-efficacy is one of the main contributors to behavior change and has been found to be a strong predictor of success in achieving physical activity goals [6]. Young adolescents with a strong sense of self-efficacy are more likely to challenge themselves with difficult tasks and are more likely to engage in walking behavior [20]. Body image is multidimensional construct that refers to how people think, feel, and behave with regard to their own physical attributes [27]. Body image is not directly included as an influential psychosocial construct in the theories and models used in behavioral and social science research on physical activity. However, many studies have indicated positive relationships between body image and physical activity in adolescents $[4,15]$. Physical activity enjoyment is a determinant of level of physical activity that does not derive directly from any of the behavioral theories and models. Enjoyment is one of the most common motives and an important factor in leisure-time physical activity participation and maintenance [26]. Expected enjoyment from physical activity can increase exercise intentions [32], but the anticipation of negative emotions is associated with weaker leisure-time physical activity intentions and behavior [37].

Based on previous research [13], we were looking for an optimal goal-setting strategy to improve correlates of physical activity. Therefore, the aim of the study was to assess the effects of an eight-week pedometer-based walking intervention in the school setting with the implementation of predetermined goals and a "do your best" strategy of goal setting, on self-efficacy, physical activity enjoyment, and body image in 16- to 18-year-old girls.

\section{Material and methods}

\section{Participants}

The study included data from 82 girls. Voluntary participants were recruited from a public high school to take part in two kinds of interventions. Twenty-six participants [age $17.3 \pm 0.89$ years; body mass $57.44 \pm 9.58 \mathrm{~kg}$; body height $166.46 \pm 5.70 \mathrm{~cm}$; BMI $\left.20.70 \pm 2.82 \mathrm{~kg} / \mathrm{m}^{2}\right]$ took part in an eight-week walking-based intervention using pedometers and a goal-setting strategy with "do your best" (do your best group). Fifty-six participants [age $17.2 \pm 0.94$ years; body mass $59.37 \pm 15.99 \mathrm{~kg}$; body height $163.17 \pm 6.11 \mathrm{~cm}$; BMI $22.21 \pm 5.15 \mathrm{~kg} / \mathrm{m}^{2}$ ] took part in an equally long intervention using pedometers and a goal-setting strategy with steps goals predetermined by the researcher (predetermined goals group). There were no significant differences in body mass, body height and BMI between the do your best group and the predetermined goals group before the intervention. Participants from the predetermined goals group were divided into two subgroups: 1) the predetermined goals group - GA (GA - goals achieved), which was formed by the 28 girls who achieved the goals set by the researcher and increased the number of steps in the consecutive eight weeks, 2) the predetermined goals group - GNA (GNA - goals not achieved), which was formed by the 28 girls who did not achieve the goals.

The study protocol was approved by the Local Bioethics Committee of The Karol Marcinkowski University of Medical Sciences in Poznań (decision no. 893/12).

\section{Intervention}

Psychological variables were measured before and after the intervention. After taking measurements, participants completed a baseline week wearing a pedometer. This initial week was introduced to allow the girls to accurately assess their baseline number of steps. The participants then wore the pedometer for the next seven weeks. Based on the baseline value of the number of steps, each study participant from the predetermined goals group received her own plan (based on the number of steps measured in the baseline week) outlining the goals to achieve for each week of the intervention. The goals were predetermined by the researcher and different for each participant, depending on the baseline number of steps. The goals were predetermined progressively, from the execution of an additional $10 \%$ in the second week, $15 \%$ in the third and fourth week, $20 \%$ in the fifth and sixth week, to $25 \%$ in the seventh and eighth week over the original number of steps. Each participant had a personal plan for every week of the intervention and could compare the weekly goal set with the actual number of steps performed during that week. The lack of goal fulfillment in one week did not 
reduce the number of steps scheduled for the next week. The girls were not evaluated positively or negatively in implementing the planned number of steps or not achieving their goals.

Participants from the do your best group after the baseline week were given one goal after the collection of baseline measurements: to do their best. The only feedback was the information from pedometers concerning the number of steps that participants performed.

\section{Step count measurement}

Individuals taking part in the study wore pedometers constantly, with the exception of time spent sleeping, swimming, and showering. The number of steps was measured with a Yamax Digi-Walker SW 701 pedometer. This pedometer has been found to be a reliable instrument for measuring walking-type movements [34]. Data from the pedometers were collected once a week during physical education classes by the physical education teacher.

\section{Psychological variables measure}

Self-efficacy. Self-efficacy was assessed using a SelfEfficacy Questionnaire [25]. The questionnaire consisted of eight items, e.g. I can be physically active during my free time on most days. A three-point Likert scale was used [38]. It was possible to obtain 24 points in total on this scale. A higher score indicated better self-efficacy. Evidence for the factorial validity of the questionnaire was provided [25]. In the present study, the internal consistency of the scale established with the Cronbach's alpha test was 0.67 .

Enjoyment of physical activity. A Physical Activity Enjoyment Scale was used to assess enjoyment of physical activity [24]. It consisted of 16 items, e.g. When I am active: I feel bored, I enjoy it. A five-point Likert scale was used. It was possible to obtain a maximum of 80 points on this scale. A higher score indicated better enjoyment of physical activity. Evidence for the factorial validity and the construct validity indicates that the scale is a valid measure of the physical activity enjoyment [24]. In the present study, the internal consistency of the scale established with the Cronbach's alpha test was 0.90 .

Body image. Body image was assessed using the feelings and attitudes towards the body scale included in the Body Investment Scale developed by Orbach and Mikulincer [29]. Feelings and attitudes towards the body scale comprise six statements (e.g. I like my appearance in spite of its imperfections, I am satisfied with my appearance) each scored on a 5-item scale. Consequently, the global score ranged from 0 to 24 points. A higher global score indicated a more positive body image. In our previous study [14] internal consistency of the scale established with the Cronbach's alpha test was 0.91 .

\section{Statistical analysis}

Analysis was carried out in two phases. In the first phase, the effects of interventions on the investigated variables between the predetermined goals group and do your best group were compared. In the second phase, the predetermined goals group was divided into the predetermined goals group - GA and the predetermined goals group - GNA. Therefore, in the second phase of the analysis, effects of interventions on the investigated variables were assessed in three groups: predetermined goals group - GA, predetermined goals group - GNA and do your best group.

Calculations were performed using STATISTICA 10 (StatSoft, Inc.). The t-test was used to evaluate differences in body weight, body height and BMI between groups before the intervention. In order to investigate the differences both between the results obtained before and after the intervention and between groups (separately for number of steps, enjoyment of physical activity, self-efficacy and body image), ANOVA with repeated measures (terms $x$ groups) was employed. To conduct detailed multiple comparisons, Tukey's post-hoc test was used. Eta-squared $\left(\eta^{2}\right)$ was calculated to determine the effect size for particular effects.

\section{Results}

\section{First phase of analysis}

Table 1 shows descriptive statistics and the results of ANOVA of the investigated variables. There were no significant differences in enjoyment of physical activity $\left(\mathrm{F}=1.43, \mathrm{p}=0.24, \eta^{2}=0.02\right)$, self-efficacy $(\mathrm{F}=0.01$, $\left.\mathrm{p}=0.91, \eta^{2}<0.001\right)$, or body image $(\mathrm{F}=2.12, \mathrm{p}=0.15$, $\eta^{2}=0.03$ ) between the results obtained before and after the intervention, as well as between the predetermined goals group and the do your best group.

Figure 1 shows the mean values of the number of steps achieved during the intervention in the predetermined goals group and the do your best group. There were no significant differences in the level of physical activity monitored using pedometers either between weeks of interventions or between groups $\left(F=3.10, p=0.82, \eta^{2}=0.006\right)$.

\section{Second phase of analysis}

Figure 2 shows the achieved level of physical activity during the intervention represented by the number of steps in the three groups: predetermined goals group - GA, predetermined goals group - GNA and do your best group. The results of ANOVA with repeated measures in the three groups showed statistical differences $(\mathrm{F}=2.84, \mathrm{p}<0.001$, 
Table 1. Descriptive statistics and results of ANOVA of variables before and after intervention in the predetermined goals group and the do your best group

\begin{tabular}{|c|c|c|c|c|c|}
\hline \multirow{2}{*}{ Variables } & \multirow{2}{*}{$\begin{array}{c}\text { Pretest } \\
\mathrm{M} \pm \mathrm{SD}\end{array}$} & \multirow{2}{*}{$\frac{\text { Posttest }}{\mathrm{M} \pm \mathrm{SD}}$} & \multicolumn{3}{|c|}{ ANOVA } \\
\hline & & & $\mathrm{F}$ & $\mathrm{p}$ & $\eta^{2}$ \\
\hline \multicolumn{6}{|c|}{ Enjoyment of physical activity (pts) } \\
\hline Predetermined goals group & $61.4 \pm 10.5$ & $63.3 \pm 13.0$ & \multirow{2}{*}{1.43} & \multirow{2}{*}{0.24} & \multirow{2}{*}{0.02} \\
\hline Do your best group & $63.9 \pm 9.1$ & $62.9 \pm 9.0$ & & & \\
\hline \multicolumn{6}{|l|}{ Self-efficacy (pts) } \\
\hline Predetermined goals group & $19.8 \pm 2.5$ & $20.3 \pm 4.2$ & \multirow{2}{*}{0.01} & \multirow{2}{*}{0.91} & \multirow{2}{*}{$<0.001$} \\
\hline Do your best group & $19.4 \pm 3.6$ & $19.9 \pm 2.6$ & & & \\
\hline \multicolumn{6}{|l|}{ Body image (pts) } \\
\hline Predetermined goals group & $20.8 \pm 5.5$ & $20.8 \pm 6.0$ & \multirow{2}{*}{2.12} & \multirow{2}{*}{0.15} & \multirow{2}{*}{0.03} \\
\hline Do your best group & $17.9 \pm 7.2$ & $19.8 \pm 7.6$ & & & \\
\hline
\end{tabular}

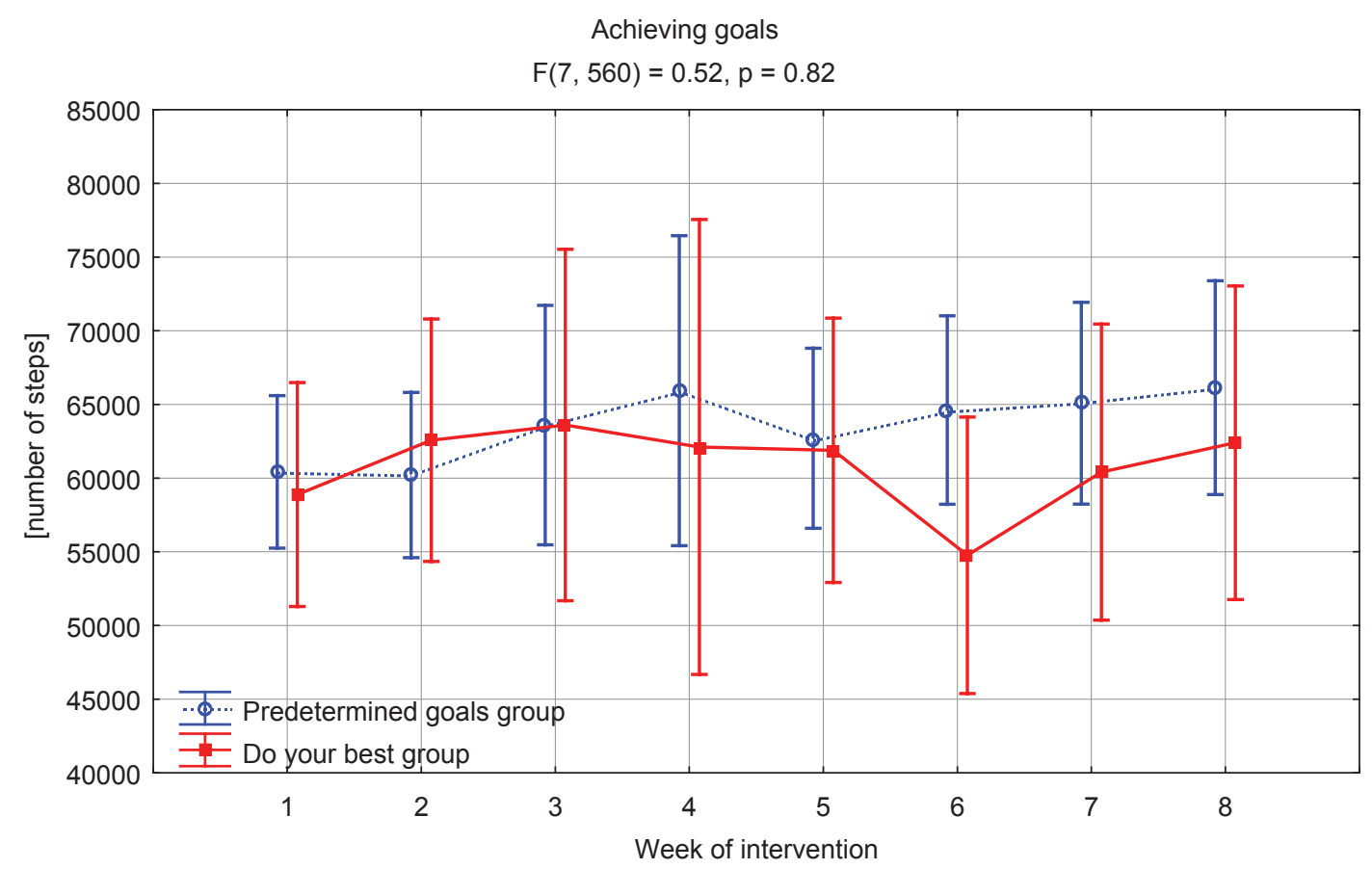

Fig. 1. Number of steps in consecutive weeks of intervention in the predetermined goals group and the do your best group

$\left.\eta^{2}=0.067\right)$ in step counts. Post hoc tests revealed significant differences between baseline and the last week of the intervention in the predetermined goals group - GA $(\mathrm{p}<0.01)$ and between the predetermined goals group $G A$ and the predetermined goals group - GNA in the last week of the intervention $(\mathrm{p}<0.001)$.

Table 2 presents the descriptive statistics and ANOVA results of variables in the predetermined goals group $G A$, the predetermined goals group - GNA and the do your best group. The results of ANOVA with repeated measures in the three groups showed statistical differences in physical activity enjoyment $\left(\mathrm{F}=3.10, \mathrm{p}=0.05, \eta^{2}=0.07\right)$. Post hoc tests indicated a higher level of enjoyment of physical activity in the predetermined goals group - GA after the intervention than in the predetermined goals group - GNA in the baseline week $(\mathrm{p}<0.05)$ and during the last week of the intervention $(\mathrm{p}<0.001)$.

There was no significant interaction effect in self-effi$\operatorname{cacy}\left(\mathrm{F}=1.76, \mathrm{p}=0.18, \eta^{2}=0.04\right)$ between either the times of measurement or groups (Table 2). The level of body image before and after the intervention in the three groups was significantly different $\left(F=3.60, p=0.03, \eta^{2}=0.08\right)$. Post hoc tests did not indicate differences between times of measurement or groups. After the end of the intervention, compared to baseline value, levels of body image in groups achieving the goals set in the intervention (predetermined goals group - GA and do your best group) were higher than in the predetermined group - GNA. 


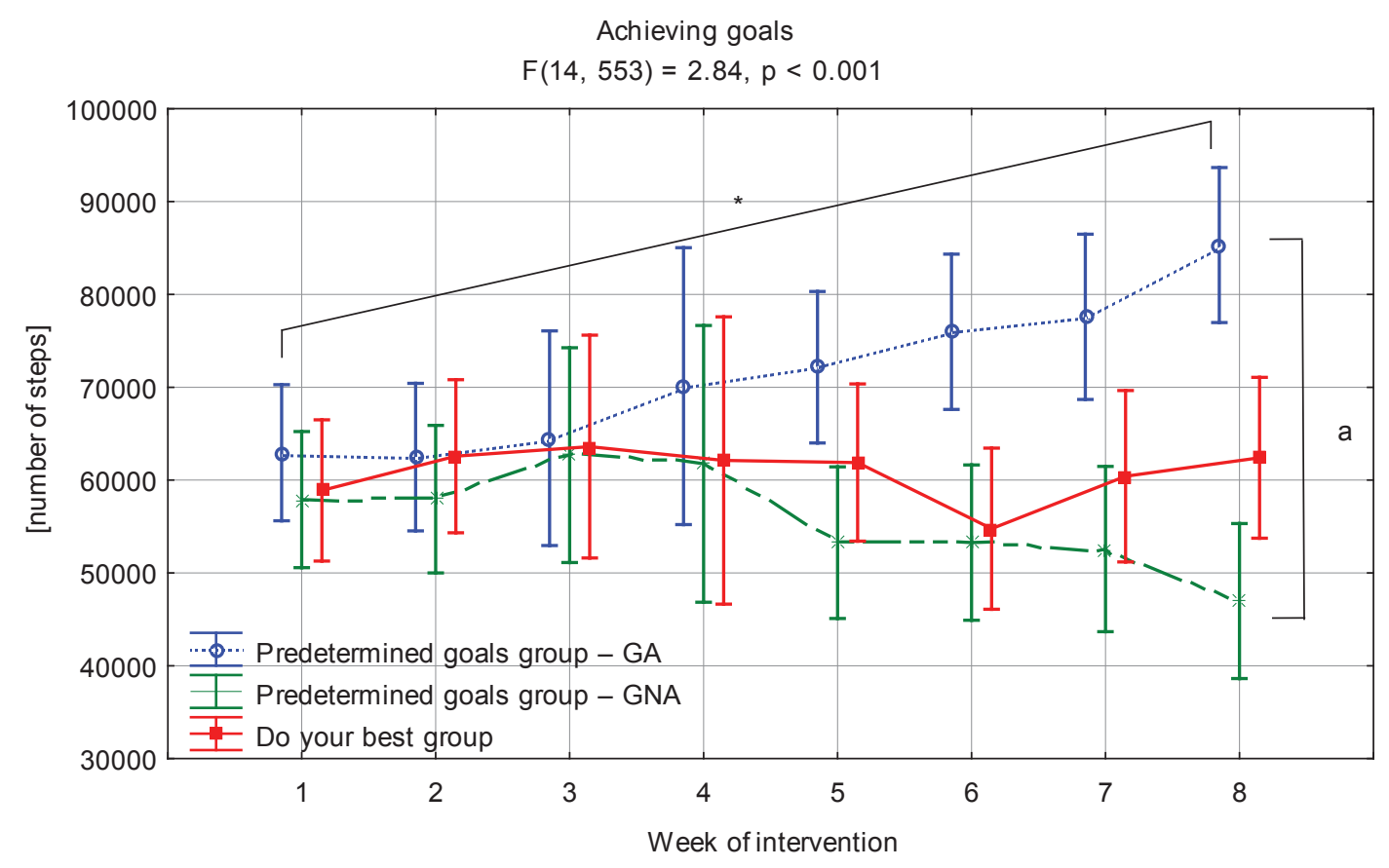

Fig. 2. Number of steps in consecutive weeks intervention in the predetermined goals group - GA (goals achieved), the predetermined goals group - GNA (goals not achieved), and the do your best group; * differences between baseline and the last week of intervention $(\mathrm{p}<0.01)$ in the predetermined goals group $-G A,{ }^{\text {a }}$ difference between the predetermined goals group - GA and the predetermined goals group - GNA $(\mathrm{p}<0.001)$ in the eighth week

Table 2. Descriptive statistics and results of ANOVA of variables before and after intervention in predetermined goals group - GA (goals achieved), predetermined goals group - GNA (goals no achieved) and do your best group

\begin{tabular}{|c|c|c|c|c|c|}
\hline \multirow{2}{*}{ Variables } & \multirow{2}{*}{$\frac{\text { Pretest }}{\mathrm{M} \pm \mathrm{SD}}$} & \multirow{2}{*}{$\begin{array}{l}\text { Posttest } \\
\mathrm{M} \pm \mathrm{SD}\end{array}$} & \multicolumn{3}{|c|}{ ANOVA } \\
\hline & & & $\mathrm{F}$ & $\mathrm{p}$ & $\eta^{2}$ \\
\hline \multicolumn{6}{|l|}{ Enjoyment of physical activity (pts) } \\
\hline Predetermined goals group - GA & $63.6 \pm 8.9$ & $68.5 \pm 8.5$ & & & \\
\hline Predetermined goals group - GNA & $59.3 \pm 11.6$ & $58.3 \pm 14.7$ & 3.10 & 0.05 & 0.07 \\
\hline Do your best group & $63.9 \pm 9.1$ & $62.9 \pm 9.0$ & & & \\
\hline \multicolumn{6}{|l|}{ Self-efficacy (pts) } \\
\hline Predetermined goals group - GA & $20.2 \pm 2.4$ & $21.6 \pm 3.6$ & & & \\
\hline Predetermined goals group - GNA & $19.5 \pm 2.5$ & $19.1 \pm 4.5$ & 1.76 & 0.18 & 0.04 \\
\hline Do your best group & $19.4 \pm 3.6$ & $19.9 \pm 2.6$ & & & \\
\hline \multicolumn{6}{|l|}{ Body image (pts) } \\
\hline Predetermined goals group - GA & $20.6 \pm 6.1$ & $22.3 \pm 5.1$ & & & \\
\hline Predetermined goals group - GNA & $20.9 \pm 5.0$ & $19.4 \pm 6.4$ & 3.60 & 0.03 & 0.08 \\
\hline Do your best group & $17.9 \pm 7.2$ & $19.8 \pm 7.6$ & & & \\
\hline
\end{tabular}

\section{Discussion}

We sought to discover whether a goal-setting strategy with two different variants (predetermined goals and "do your best" goals) will be motivating for adolescent girls. Research shows that improvement in health outcomes can be achieved even with an increase of as little as 2500 steps/ day over the baseline [36]. Designing an optimal strategy for an intervention that increases leisure-time physical activity across age groups and sexes seems challenging. In our study, we observed no differences in the number of steps between the two analyzed groups (do you best and predetermined goal). However, changes were observed in the levels of steps and examined psychological variables (body image and enjoyment of PA), when we took into 
account whether the predetermined goals of intervention were achieved by adolescents or not.

A study by Dishman et al. [8] provided evidence that the manipulation of self-efficacy results increases physical activity among adolescent girls. It was found that using self-efficacy as a targeted mediator variable in interventions designed to increase physical activity among girls partially mediates the effects. It was therefore interesting to investigate the changes in the level of self-efficacy in goal setting design, in which there was no manipulation of the variable. The analysis of the results from this study showed that there was no significant difference in self-efficacy between the examined groups. The differences in the level of that particular variable were also not observed in adjusted analysis, when a group of girls who did not maintain goal achievement was subtracted. This may be due to the self-efficacy concept, which seems to be a fairly stable psychological property [23]. The changes in the level of self-efficacy noted in other studies appeared when the experiments were designed to provide an educational impact and psychological support concerning self-efficacy, which was correlated with increasing levels of physical activity [17]. It is also possible that a longer intervention in our study could bring about a better effect even without educational or psychological support, because the mean of the results shows this tendency (decreasing in the predetermined goals group - GNA and increasing in the predetermined goals group - GA). The information and feedback that an individual obtains from the performance of a task is referred to as the sources of self-efficacy [1], such as positive experiences of performing a behavior, as in our study. Findings from Łuszczyńska et al. [22] emphasize that people who report low perceived self-efficacy may not benefit from interventions designed to promote physical activity. This could also be the reason why planning the activity (via the goal setting strategy) is not sufficient to increase physical activity, an effect that could be mitigated by adding self-efficacy interventions while planning interventions [21]. Lack of increase in self-efficacy may also be due to the initially high level of this parameter at the start of the intervention. In other studies concerning the same age category, the level of self-efficacy in young individuals was lower [e.g., 21].

However, the adjusted analysis provided some other important findings. Body image was associated with achieving the goals by participants from the predetermined goals group and the do your best group, whereas physical activity enjoyment increased only in the predetermined goals group - GA. Dishman et al. [8] provided evidence from an experimental study with randomized trials linking increased physical activity enjoyment with increased physical activity, influenced by self-efficacy.
In our previous study [13] we observed that positive experiences, such as achieving the goals set concerning physical activity in the goal setting experiment, are usually associated with higher levels of physical activity enjoyment. The do your best strategy did not bring about these effects in the present study. Achieving predetermined goals was associated with an increase in physical activity enjoyment, which could have been the effect of satisfaction at fulfilling the tasks, in comparison to the do your best group, which had no set goals concerning the number of steps to achieve. We can say that in regards to increasing physical activity, the do your best strategy does not appear to be optimal. Young people seem to be more motivated by well-defined, specific and personalized goals. For girls, enjoyment is an extremely important intrinsic motivation for being active. Reeve and Deci [31] have argued convincingly that intrinsically motivated people engage in physical activity for the sake of fun and personal improvement. Although pedometers may be a helpful and quite handy tool for setting step goals as they provide real-time feedback on physical activity, for achieving long-term health effects behavioral change techniques are vital, specifically with adolescents. It seems from our data that for youth, the process of achieving the goals may be more valued than the set goals themselves, and as such it requires constant teacher support. It is also possible that there are other influential factors that play a mediating role in the level of adolescent girls' physical activity.

It was found that girls differed significantly in their attitudes towards caring about being healthy, being fit and exercising. Those without high body satisfaction were less likely to report caring about their weight [16]. In a study by Pearson and Hall [30], a significant relationship between body image and self-determined forms of exercise motivation was found. It was also observed that overweight and obese female participants in an 18-week cardiovascularbased program felt they were increasingly investing in being physically fit up to week 12 of the program, which had an impact on their motivation. This derived from increased feelings of satisfaction with overall and specific aspects of their appearance and physical attractiveness. After this time (12 weeks), there was no further significant enhancement in body image.

The idea and the nature of the goals set were similar in our study, but it is worth noting that the evaluation of goal achievement was mostly subjective, specifically for the do your best group. The findings may indicate that not achieving goals coupled with lower physical activity can negatively influence body image perception. To change the body image perception, the most important factor was activity - being physically active - not just achieving the goals, which is likely the reason that body image 
perception was positively influenced in both the do your best group and the predetermined goals group - GA. The negative feedback of failing to achieve the goals could have negatively affected body image among girls in the predetermined goals group - GNA. It might also be that those girls did not feel they were investing in their body image and therefore did not follow external goals as they did not endorse their importance on a personal level. Similar results were obtained in research by Ryan, Patrick, Deci, and Williams [33]. Additionally, body weight status and body change during intervention could influence perception of body image in girls. In a cross-sectional study we observed that adolescent girls with underweight showed the most positive body satisfaction and girls with overweight the most negative body satisfaction [14].

The results of the present study are informative. The strengths of our study are the identification of phases in analysis, which revealed a more complex association between the studied variables, and the comparison of two different goal setting strategies, which made it possible to analyze the effectiveness of each strategy in a school setting. The limitations of our study are connected with a relatively small experimental, non-random group, which may have impacted the findings. There is also a question on the accuracy of the measuring equipment used. Pedometers allow one to evaluate the number of steps but not the intensity of physical activity. However, according to Lubans, Morgan and Tudor-Locke [19], using pedometers with reasonable accuracy is a promising strategy for promotion of PA among adolescents in school settings. Investigating relationships between self-efficacy, physical activity enjoyment, and body image may lead to identifying an optimal strategy for increasing physical activity of adolescent girls. Other studies [2, 12] show that having a step goal might be an important predictor for enhancement of the increase of physical activity during pedometer interventions.

\section{Conclusions}

The results of our study showed that an eight-week pedometer-based walking program implemented in a school setting may improve body image and physical activity enjoyment in adolescent girls only if the set goals (the number of steps) are specific and fully achieved by the participants. Additionally, using pedometers in conjunction with a goal setting program seems to be an effective motivational way to improve physical activity in female students. The results may be of interest to researchers working on health behavior of adolescents, physical education teachers, and physical activity intervention designers.
Conflict of interest: Authors state no conflict of interest.

\section{References}

1. Bandura A. (1997) Self-efficacy: The Exercise of Control. Freeman, New York.

2. Bravata D.M., Smith-Spangler C., Sundaram V., Gienger A.L., Lin N., Lewis R., Stave C.D., Olkin I., Sirard J.R. (2007) Using pedometers to increase physical activity and improve health: a systematic review. JAMA, 298: 2296-2304. DOI: 10.1001/jama.298.19.2296.

3. Camacho-Miñano M.J., LaVoi N.M., Barr-Anderson D.J. (2011) Interventions to promote physical activity among young and adolescent girls: a systematic review. Health Educ. Res., 26: 1025-1049. DOI: 10.1093/her/cyr040.

4. Campbell A., Hausenblas H.A. (2009) Effects of exercise interventions on body image: A metaanalysis. J. Health Psychol., 14: 780-793. DOI: 10.1177/1359105309338977.

5. Currie C., Gabhainn S.N., Godeau E., Roberts C., Smith R., Currie D., Picket W., Richter M., Morgan A., Barnekow V. (2008) Inequalities in young people's health. Health behaviour in school-aged children: International report from the 2005/2006 survey. (Health Policy for Children and Adolescents, No. 5). WHO Regional Office for Europe, Copenhagen.

6. David P., Pennell M.L., Foraker R.E., Katz M.L., Buckworth J., Paskett E.D. (2014) How are previous physical activity and self-efficacy related to future physical activity and self-efficacy? Health Educ. Behav., 41: 573-576. DOI: $10.1177 / 1090198114543004$.

7. Demetriou Y., Höner O. (2012) Physical activity interventions in the school setting: a systematic review. Psychol. Sport. Exerc., 13: 186-196. DOI: 10.1016/j. psychsport.2011.11.006.

8. Dishman R.K., Motl R.W., Saunders R., Felton G., Ward D.S., Dowda M., Pate R.R. (2004) Self-efficacy partially mediates the effect of a school-based physicalactivity intervention among adolescent girls. Prev. Med., 38: 628-636. DOI: 10.1016/j.ypmed.2003.12.007.

9. Fogelholm M. (2010) Physical activity, fitness and fatness: relations to mortality, morbidity and disease risk factors. A systematic review. Obes. Rev., 11: 202-221. DOI: 10.1111/j.1467-789X.2009.00653.x.

10. Grant E.M., Young D.R., Wu T.T. (2015). Predictors for physical activity in adolescent girls using statistical shrinkage techniques for hierarchical longitudinal mixed effects models. PLoS ONE, 10(4): e0125431. DOI: 10.1371/journal.pone.0125431.

11. Kahn E.B., Ramsey L.T., Brownson R.C., Heath G.W., Howze E.H., Powell K.E., Stone E.J., Rajab M.W., Corso P. (2002) The effectiveness of interventions to increase 
physical activity. A systematic review. Am. J. Prev. Med., 22: 73-107. DOI: 10.1016/S0749-3797(02)00434-8.

12. Kang M., Marshall S.J., Barreira T.V., Lee J.-O. (2009) Effect of pedometer-based physical activity interventions: a meta-analysis. Res. Q. Exerc. Sport., 80: 648-655. DOI: 10.1080/02701367.2009.10599604.

13. Kantanista A., Bronikowski M., Laudanska-Krzeminska I., Osinski W. (2014) Effects of pedometer-based walking intervention on psychological and biological variables in adolescent girls: does achieving goals make a difference? Med. Sport., 67(2): 261-272.

14. Kantanista A., Król-Zielińska M., Borowiec J., Osiński W. (2017) Is underweight associated with more positive body image? Results of a cross-sectional study in adolescent girls and boys. Span. J. Psychol., 20. DOI: 10.1017/ sjp.2017.4.

15. Kantanista A., Osiński W., Borowiec J., Tomczak M., Król-Zielińska M. (2015) Body image, BMI, and physical activity in girls and boys aged 14-16 years. Body image, 15: 40-43. DOI: 10.1016/j.bodyim.2015.05.001.

16. Kelly A.M., Wall M., Eisenberg M.E., Story M., Neumark-Sztainer D. (2005) Adolescent girls with high body satisfaction: who are they and what can they teach us? J. Adolesc. Health, 37: 391-396. DOI: 10.1016/j. jadohealth.2004.08.008.

17. Lee L.L., Kuo Y.C., Fanaw D., Perng S.J., Juang I.F. (2011) The effect of an intervention combining self-efficacy theory and pedometers on promoting physical activity among adolescents. J. Clin. Nurs., 21: 914-922. DOI: 10.1111/j.1365-2702.2011.03881.x.

18. Locke E.A., Latham G.P. (2006) New directions in goalsetting theory. Curr. Dir. Psychol. Sci., 15: 265-68. DOI: 10.1111/j.1467-8721.2006.00449.x.

19. Lubans D.R., Morgan P.J., Tudor-Locke C. (2009) A systematic review of studies using pedometers to promote physical activity among youth. Prev. Med., 48: 307-315. DOI: 10.1016/j.ypmed.2009.02.014.

20. Lutes L., Steinbaugh E. (2010) Theoretical models for pedometer use in physical activity interventions. Phys. Ther. Rev., 15: 143-153. DOI: 10.1179/1743288X10Y.0000000002.

21. Łuszczyńska A., Tryburcy M., Schwarzer R. (2007) Improving fruit and vegetable consumption: A self-efficacy intervention compared to a combined self-efficacy and planning intervention. Health Educ. Res., 22: 630-638. DOI: $10.1093 /$ her/cyl133.

22. Łuszczyńska A., Schwarzer R., Lippke S., Mazurkiewicz M. (2011) Self-efficacy as a moderator of the planning-behaviour relationship in interventions designed to promote physical activity. Psychol. Health, 26: 151-166. DOI: 10.1080/08870446.2011.531571.

23. Motl R.W., Dishman R.K., Ward D.S., Saunders R.P., Dowda M., Felton G., Pate R.R. (2005) Comparison of barriers self-efficacy and perceived behavioral control for explaining physical activity across 1 year among adolescent girls. Health Psychol., 24: 106-111. DOI: 10.1037/0278-6133.24.1.106.

24. Motl R.W., Dishman R.K., Saunders R., Dowda M., Felton G., Pate R.R. (2001) Measuring enjoyment of physical activity in adolescent girls. Am. J. Prev. Med., 21: 110-117. DOI: 10.1016/S0749-3797(01)00326-9.

25. Motl R.W., Dishman R.K., Trost S.G., Saunders R.P., Dowda M., Felton G., Ward D.S., Pate R.R. (2000) Factorial validity and invariance of questionnaires measuring social-cognitive determinants of physical activity among adolescent girls. Prev. Med., 31: 584-594. DOI: 10.1006/ pmed.2000.0735.

26. Mullen S.P., Olson E.A., Phillips S.M., Szabo A.N., Wójcicki T.R., Mailey E.L., Gothe N.P., Fanning J.T., Kramer A.F., McAuley E. (2011) Measuring enjoyment of physical activity in older adults: invariance of the physical activity enjoyment scale (paces) across groups and time. Int. J. Behav. Nutr. Phys. Act., 8: 103. DOI: 10.1186/1479-5868-8-103.

27. Muth J.L., Cash T.F. (1997) Body-image attitudes: What difference does gender make? J. Appl. Soc. Psychol., 27: 1438-1452. DOI: 10.1111/j.1559-1816.1997.tb01607.x.

28. Naylor P.J., McKay H.A. (2009) Prevention in the first place: schools a setting for action on physical inactivity. Br. J. Sports Med., 43: 10-13. DOI: 10.1136/ bjsm.2008.053447.

29. Orbach I., Mikulincer M. (1998) The Body Investment Scale: Construction and validation of a body experience scale. Psychol. Assessment., 10: 415-425. DOI: 10.1037/1040-3590.10.4.415.

30. Pearson E.S., Hall C.R. (2013) Examining body image and its relationship to exercise motivation: an 18-week cardiovascular program for female initiates with overweight and obesity. Balt. J. Health Phys. Act., 5: 121-131. DOI: 10.2478/bjha-2013-0012.

31. Reeve J., Deci E.L. (1996) Elements of the competitive situation that affect intrinsic motivation. Pers. Soc. Psychol. Bull., 22: 24-33. DOI: 10.1177/ 0146167296221003.

32. Ruby M.B., Dunn E.W., Perrino A., Gillis R., Viel S. (2011) The invisible benefits of exercise. Health Psychol., 30: 67-74. DOI: 10.1037/a0021859.

33. Ryan R.M., Patrick H., Deci E.L., Williams G.C. (2008) Facilitating health behavior change and its maintenance: Interventions based on self-determination theory. Eur. Health Psychol., 10: 2-5.

34. Schneider P.L., Crouter S.E., Lukajic O., Bassett D.R. (2003) Accuracy and reliability of 10 pedometers for measuring steps over a 400-m walk. Med. Sci. Sports Exerc., 35: 1779-1784. DOI: 10.1249/01. MSS.0000089342.96098.C4.

35. Shilts M.K., Horowitz M., Townsend M.S. (2004) Goal setting as a strategy for dietary and physical activity 
behavior change: a review of the literature. Am. J. Health Behav., 19: 81-93.

36. Sugiura H., Kajima K., Mirbod S.M., Iwata H., Matsuoka T. (2002) Effects of long-term exercise and increase in number of daily steps on serum lipids in women: randomised controlled trial [ISRCTN21921919]. BMC Womens Health, 2: 3. DOI: 10.1186/1472-6874-2-3.

37. Wang X. (2011) The role of anticipated negative emotions and past behavior in individuals' physical activity intentions and behaviors. Psychol Sport Exerc., 12: 300-305. DOI: 10.1016/j.psychsport.2010.09.007.
38. Ward D.S., Saunders R.P., Pate R.R.(2007) Physical activity interventions in children and adolescents. New World Library.

Received 29.12.2016
Accepted 22.03.2017

(C) University of Physical Education, Warsaw, Poland 